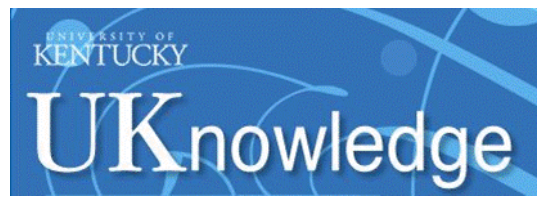

University of Kentucky

UKnowledge

Center for Health Services Research Faculty

Publications

Center for Health Services Research

$10-1-2017$

\title{
Heroin Use Onset Among Nonmedical Prescription Opioid Users in the Club Scene
}

\author{
Hilary L. Surratt \\ University of Kentucky, hilary.surratt@uky.edu \\ Steven P. Kurtz \\ Nova Southeastern University \\ Mance Buttram \\ Nova Southeastern University \\ Maria A. Levi-Minzi \\ Nova Southeastern University \\ Maria E. Pagano \\ Case Western Reserve University \\ Follow this and additional works at: https://uknowledge.uky.edu/chsr_facpub \\ See next page for additional authors \\ Part of the Behavior and Behavior Mechanisms Commons, Health Services Research Commons, \\ Pharmacy Administration, Policy and Regulation Commons, and the Substance Abuse and Addiction \\ Commons
}

Right click to open a feedback form in a new tab to let us know how this document benefits you.

\section{Repository Citation}

Surratt, Hilary L.; Kurtz, Steven P.; Buttram, Mance; Levi-Minzi, Maria A.; Pagano, Maria E.; and Cicero, Theodore J., "Heroin Use Onset Among Nonmedical Prescription Opioid Users in the Club Scene" (2017). Center for Health Services Research Faculty Publications. 4.

https://uknowledge.uky.edu/chsr_facpub/4

This Article is brought to you for free and open access by the Center for Health Services Research at UKnowledge. It has been accepted for inclusion in Center for Health Services Research Faculty Publications by an authorized administrator of UKnowledge. For more information, please contact UKnowledge@lsv.uky.edu. 


\section{Heroin Use Onset Among Nonmedical Prescription Opioid Users in the Club Scene}

\section{Digital Object Identifier (DOI)}

https://doi.org/10.1016/j.drugalcdep.2017.06.034

Notes/Citation Information

Published in Drug and Alcohol Dependence, v. 179, p. 131-138.

(C) 2017 Elsevier B.V. All rights reserved.

This manuscript version is made available under the CC-BY-NC-ND 4.0 license

https://creativecommons.org/licenses/by-nc-nd/4.0/.

The document available for download is the author's post-peer-review final draft of the article.

Authors

Hilary L. Surratt, Steven P. Kurtz, Mance Buttram, Maria A. Levi-Minzi, Maria E. Pagano, and Theodore J. Cicero 


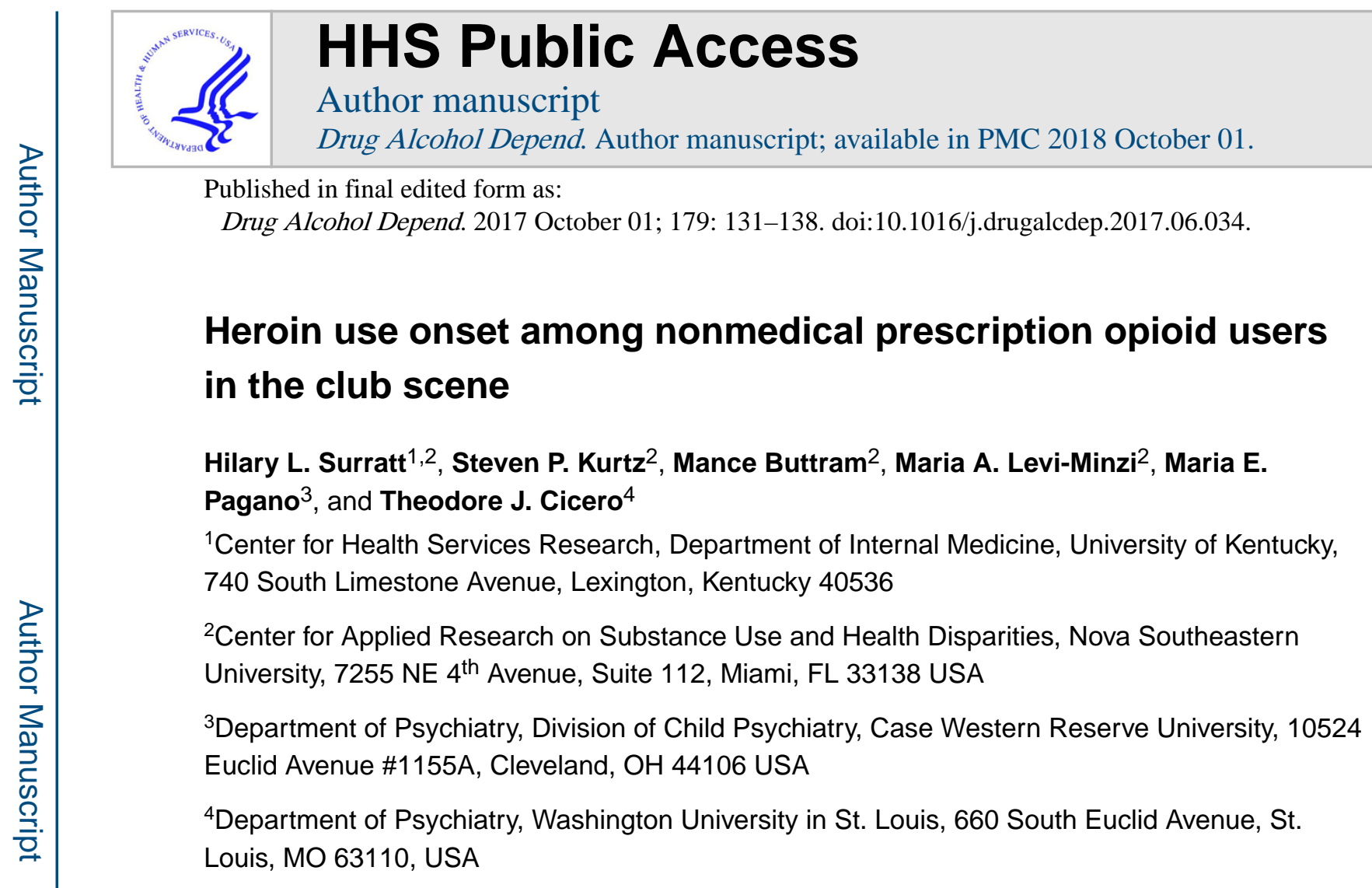

\section{Abstract}

Background-Nonmedical prescription opioid use (NMPOU) is well documented among participants in the club scene, yet prior studies have not examined transition to heroin use. We prospectively examined heroin initiation among a sample of young adults with drug involvement associated with participation in the club scene, to understand factors that influence transition from NMPOU to heroin and to identify opportunities for intervention.

Methods-Data were drawn from a randomized trial that enrolled 750 Miami-based club and prescription drug users through respondent driven sampling, and tested the efficacy of assessment interventions in reducing risk. Participants reported current substance use at baseline, 3, 6, and 12 month follow-ups. We examined predictors of heroin initiation among participants reporting NMPOU at baseline, with no lifetime history of heroin use ( $\mathrm{N}=323)$.

Results-The mean age was 25.0 years; $67.5 \%$ met DSM-IV criteria for substance dependence. About 1 in 13 participants (7.7\%) initiated heroin use at follow-up. In univariable comparisons,

Correspondence: Hilary L. Surratt, Ph.D., Center for Health Services Research, Department of Internal Medicine, University of Kentucky, 740 South Limestone Avenue, J516, Lexington, Kentucky 40536, hilary.surratt@uky.edu, Tel: (859) 218-4964, Fax: 859-257-0521.

Publisher's Disclaimer: This is a PDF file of an unedited manuscript that has been accepted for publication. As a service to our customers we are providing this early version of the manuscript. The manuscript will undergo copyediting, typesetting, and review of the resulting proof before it is published in its final citable form. Please note that during the production process errors may be discovered which could affect the content, and all legal disclaimers that apply to the journal pertain.

Author Disclosures

Contributors

All authors contributed significantly to the design, implementation, analysis, and reporting of this research. All authors have read and approved the final manuscript.

Conflict of Interest

No conflicts declared. 
frequent LSD use, history of drug overdose, high frequency NMPOU, using oral tampering methods, and endorsing a primary medical source for prescription opioids were associated with greater likelihood of heroin initiation. LSD use, oral tampering, and primary medical source were significant predictors in a Cox regression model.

Conclusions-Heroin initiation of 7.7\% suggests a high level of vulnerability for transition among young adult NMPO users in the club scene. The importance of oral tampering methods in the trajectory of NMPOU may indicate a need to further examine the role of abuse deterrent formulations in prevention efforts.

\section{Keywords}

young adults; club drugs; opioids; heroin; routes of administration; nonmedical use

\subsection{Introduction}

Nonmedical prescription opioid use (NMPOU) contributes to significant morbidity and mortality in the US (Compton et al., 2016), including dependence, overdose (Volkow and McLellan, 2016), exposure to blood-borne infections (Peters et al., 2016), and neonatal abstinence syndrome (Stover and Davis, 2015). Although the dramatic rise in NMPOU that occurred nationally from 1990 to 2010 has stabilized in recent years, the prevalence of prescription opioid use disorders and related mortality have continued to rise (Han et al., 2015; Martins et al., 2017). Young adults have been especially impacted: in 2014, 20.2\% of 18-25 year olds reported lifetime NMPOU (Center for Behavioral Health Statistics and Quality, 2015), a higher prevalence than any other age group. National surveillance data also indicate that an increasing number of young adults are heavy prescription opioid users (Jones, 2013), which has been associated with higher drug problem severity and more rapid progression to dependence (Daniulaitye et al., 2006).

Recent efforts to characterize the evolving opioid problem indicate a broad shift from prescription opioids to heroin in many areas, with increasing rates of heroin use and heroin overdose seen nationally as early as 2009 (Cicero et al., 2014; Compton et al., 2016; Muhuri et al., 2013). To a large extent, this shift has occurred in an environment of increased efforts to reduce the adverse consequences of prescription opioids (Compton et al., 2016), including improved prescriber education (Alford et al., 2015; ONDCP, 2014), strengthening of prescription drug monitoring programs (Brady et al., 2014; Davis et al., 2014; Surratt et al., 2014), targeted law enforcement activities (Florida Department of Law Enforcement, 2012; Hall, 2015; Surratt et al., 2014), abuse-deterrent opioid formulations (Cicero et al., 2012a), the development and implementation of opioid prescribing guidelines (Frieden and Houry, 2016), and stewardship programs in healthcare settings to reduce the supply of opioids (Ghafoor et al., 2013). Although there is evidence to suggest that these types of initiatives have contributed to reductions in NMPOU and diversion of prescription opioids (Delcher et al., 2015; Rutlow et al., 2015; Surratt et al., 2014) their role in rising heroin use is unclear. Observational data indicate that heroin use was increasing prior to many of these initiatives being implemented (Dart et al., 2015; Dasgupta et al., 2014).

Drug Alcohol Depend. Author manuscript; available in PMC 2018 October 01. 
A comprehensive understanding of the ordering, progression, transition, and/or co-occurring use of prescription opioids and heroin is lacking in the scientific literature, and represents an under-researched area with significant public health implications (Muhuri et al., 2013). National trend data demonstrate consistent connections between NMPOU and transition to heroin use, with heroin incidence some 19 times higher among those reporting prior nonmedical prescription opioid use than among those who do not (Muhuri et al., 2013). Adolescents and young adults appear to be especially vulnerable to the migration from prescription opioids to heroin (Cerda et al., 2015; Palamar et al., 2016). Trend data from 2002 to 2014 documented a significant temporal increase in the odds of heroin use among young adults reporting prior non-medical prescription opioid use (Martins et al., 2017). Although strong evidence suggests clear linkages between the two phenomena (Carlson et al., 2016), it has been noted that heroin use among NMPO users is rare overall, and the transition to heroin use appears to occur at a low rate (Jones, 2013).

Emerging research is examining the intersections of NMPOU and heroin use to better understand the factors that may drive transitions. Carlson and colleagues (2016) conducted a prospective natural history study of young adult illicit prescription opioid users who at baseline were not opioid dependent and had no history of heroin use. Among this sample, 7.5\% initiated heroin over a 36-month period. Key predictors of transition included route of opioid administration, early age of prescription opioid administration, and lifetime prescription opioid dependence (Carlson et al., 2016). Additional explanatory factors posited in prior research to impact this transition include frequency of NMPOU (Jones, 2013; Palamar et al., 2016), tolerance and dependence (Daniulaitye et al., 2006, Haracopos et al., 2016), market dynamics, and subjective aspects of the user experience (Cicero et al., 2014; Cicero and Ellis, 2015).

Route of administration appears to be an important contributor to the adverse health consequences associated with NMPOU (Katz et al., 2008; Surratt et al., 2011), including transition to heroin (Carlson et al., 2016). Non-oral routes of prescription opioid ingestion are not uncommon in samples of high school and college students, rural drug abusers and urban street drug users (Davis and Johnson 2008; McCabe et al., 2007; 2009; Surratt et al., 2011; Young et al., 2010) and club drug users (Buttram and Kurtz, 2016), and are associated with greater drug problem severity, including dependence and overdose, and sexual risk behaviors (Buttram and Kurtz, 2016). Because altered routes of administration provide faster drug delivery and onset, the reinforcing effects are intensified (Compton and Volkow, 2006), thereby increasing the vulnerability to addiction. Trajectory analyses of NMPOU suggest that individuals often initiate with oral use and move to more efficient routes, such as snorting and smoking, as tolerance develops (Compton et al., 2016).

Although national surveillance data and focused studies involving community samples of young adults provide evidence for a transitional pathway from NMPOU to heroin (Carlson et al., 2016; Martins et al., 2017), it is important to document rates of heroin initiation in potentially vulnerable targeted samples to identify potential need and opportunities for intervention. NMPOU is well documented among participants in the club scene (Inciardi et al., 2007; Kelly and Parsons, 2007; Kelly et al., 2015; Kurtz et al., 2005; 2013; 2017), yet prior studies have not systematically examined transition to heroin use among samples of 
club drug users. We prospectively examine the initiation of heroin use among a targeted sample of young adults with extensive, yet largely recreational, drug involvement associated with nightlife participation in the Miami club scene. Our key purposes are to investigate the initiation of heroin use over time among club goers who report NMPOU and to examine predictors of this transition that are potentially amenable to intervention.

\subsection{Methods}

\subsection{Study Site}

Miami-Dade County, Florida is a large and ethnically diverse metropolitan area with a population of 2.6 million people, of whom 66.2\% are Hispanic (U.S. Census Bureau, 2015). For decades Miami has been a key transportation hub and distribution center for illicit drugs (Allman,1987; National Drug Intelligence Center, 2003; Portes and Stepick, 1993), and is a major presence in the U.S. East Coast club scene, having become well-known for trendsetting nightlife and club drug use (Brandt, 2003; Perrone, 2009). The Miami club scene is characterized by extensive poly-drug use among its largely young aged club-goers, typically including illicit drugs and nonmedical prescription drug use as features of the club going experience (Kurtz et al., 2005; 2013; 2017).

\subsection{Study Sampling Plan}

The data for this analysis were drawn from a prospective three-armed randomized controlled trial designed to recruit a sample of 750 Miami-based club-going participants and test the relative efficacy of alternative low-intensity assessment interventions in reducing drug use and sexual risk behaviors at 3, 6 and 12 month follow-up. Eligibility criteria for trial participation were: 1) ages 18-39;2) reported use of illicit club drug(s) at least three times in the past 3 months; 3 ) reported nonmedical use of a psychoactive prescription medication at least once in the past 3 months; 4) heterosexual vaginal and/or anal sex in the past 3 months; 5) attendance at large local nightclubs at least once per month; 6) residence in metropolitan Miami; and 7) willingness to provide locator information. Endorsement of both past 90 day club drug use and nonmedical prescription drug use was required for inclusion in the intervention trial.

Study recruitment was conducted between September 2011 and November 2014 using respondent-driven sampling (RDS) techniques (Heckathorn, 1997). Seeds (initial respondents) were recruited through targeted outreach at Miami nightclub venues and contacts in the club scene derived from the authors' prior Miami-based field studies. Miami's club scene is comprised of an extensive network of large and small nightclubs clustered largely in the geographically contiguous areas of South Beach and the City of Miami, which have been mapped previously by the study investigators. Each seed and subsequent participant was provided with recruitment coupons to give to other potentially eligible drug users in their social network. Consistent with RDS procedures, each participant-recruiter in this study was limited to five coupons. 


\subsection{Study Procedures}

The study field office location was selected for accessibility to the primary transportation routes in Miami. Field staff were bi-lingual (English/Spanish) age-peers of the target population with at least a Bachelor's degree and one year of research experience, who were trained in all aspects of the research and human subjects' protocols. Field staff screened potential study participants by telephone; those who were eligible and interested in participating were scheduled for enrollment at the field office. The enrollment visit included eligibility verification, written informed consent using procedures approved by the University institutional review board, and collection of locator information.

At baseline, all participants completed a brief Risk Behavior Inventory (RBI) assessing primary substance use and sexual behavior outcomes using an ACASI-based instrument that took 10-15 minutes to complete. Participants were randomized immediately thereafter to the three study arms: 1) an interviewer-administered comprehensive health and social risk assessment intervention (CAPI Intervention); 2) a self-administered assessment intervention with identical instrumentation (ACASI Intervention); and 3) a waitlist control condition (Control). Immediately after randomization, those assigned to the CAPI or ACASI arms continued with the full assessment protocols; waitlist controls did not complete a full baseline assessment. At 3-, 6- and 12-months post-baseline, all participants again completed the brief RBI measure of primary outcome data. At 12-month follow-up, based on initial intervention assignment, appropriate comprehensive health and social risk assessments were also completed. Participants received $\$ 50$ for their time and travel costs for the baseline and each subsequent follow-up visit.

\subsection{Measures}

The assessment interventions utilized the Global Appraisal of Individual Needs (GAIN, v. 5.4; Dennis et al., 2006), which has eight core sections (background, substance use, physical health, sexual risk behaviors, mental health, victimization, criminal justice involvement, and education/work/financial stability), each assessing recency of problems, range of symptoms, and recent (90 day) and lifetime prevalence. The items include scales for Diagnostic and Statistical Manual of Mental Disorders, $4^{\text {th }}$ edition (DSM-IV)-based diagnoses.

Psychometric studies have found Cronbach's alphas between .8 and .9 for these measures. For the present study, the list of drugs was extended to include major classes of psychoactive prescription medications, and sexual behavior questions were substantially expanded using validated instruments.

\subsection{Analytic Sample Selection}

The present analysis examined prospective predictors of heroin initiation among club-going participants reporting NMPOU at baseline. Data for this analysis are limited to participants from the two active assessment intervention arms ( $\mathrm{N}=498)$ who at baseline: 1) endorsed past 90 day NMPOU ( $\mathrm{N}=446 ; 89.5 \%)$; and, 2) denied any lifetime history of heroin use ( $\mathrm{N}=369$; $74.1 \%$ ), resulting in an available $\mathrm{N}$ of 323 . Controls were excluded from the analysis due to the lack of baseline data on lifetime heroin use, as well as the NMPOU predictor variables of interest. Because the active intervention arms consisted of an equivalent low-intensity 
assessment delivered in different modalities (CAPI versus ACASI), we prospectively compare identical data points, controlling for intervention arm assignment.

\subsection{Dependent Variable}

The primary outcome measure for this study was initial use of heroin as prospectively observed among NMPO users with no prior exposure to heroin. The point in time when NMPO users initiated heroin for the first time was assessed with the question "during the past 90 days, on how many days did you use heroin?" that was collected at three follow-up intervals: (1) the 3-month assessment, (2) the 6-month assessment, and (3) the 12-month assessment. If a participant reported one or more days of heroin use at a follow-up interval, the participant was considered to have experienced the event under study (heroin initiation) and the study interval when heroin use was first endorsed was indexed. Participants who reported zero days of heroin use across intervals followed were considered to "survived" in terms of continuing to have no exposure to heroin use. Participants were censored from the analysis at the study interval where they were missing data for this assessment. Sensitivity analysis for informative censoring showed no appreciable effects on findings, and mid-level censors $(n=49)$ were representative of the sample at baseline.

\subsection{Independent Variables}

The primary independent variables for this analysis were demographics, physical and mental health status, substance use (including current use, past year dependence, and lifetime overdose, treatment and injection history) and specific features of NMPOU (length of NMPOU, frequency of NMPOU, routes of administration, and sources of opioid acquisition). The selection of independent variables for examination was largely guided by recent findings in the scientific literature documenting associations between aspects of NMPOU and heroin use initiation (Carlson et al., 2016; Cicero and Ellis, 2015; Lankenau et al., 2012). Although the role of physical and mental health issues in transition to heroin is unclear, there are well-documented connections between pain, depression and the development of opioid use disorders (Blanco et al., 2016; Salas et al., 2016). As such, we included physical and mental health measures as independent variables in our analysis.

Demographic measures included age, gender, and race/ethnicity. Race/ethnicity was assessed by asking participants to self-identify as Hispanic or Latino, followed by asking what race they considered themselves to be. Intervention arm was included as a background variable to test for intervention effects on the likelihood of heroin initiation.

For this analysis, current physical health status included two items. Physical pain was assessed by a single dichotomous item reporting whether the participant had experienced severe physical pain in the past 90 days. A second item asked participants to report whether they had experienced physical health problems that interfered with their ability to meet responsibilities in the past 90 days, as an indicator of health problem severity and impaired functioning.

Mental health status was measured using the GAIN's General Mental Distress Scale (GMDS), which includes past year DSM-IV symptom counts of depression (9 items), anxiety (12 items), and somatic disorders (four items). Alpha reliability coefficients for the 
depression, anxiety, and somaticism subscales in this study were $0.882,0.887$, and 0.801 , respectively. The GMDS has established classifications indicating clinical significance subclinical, moderate, and severe (Dennis et al., 2006). For this analysis, mental distress scores were dichotomized into "severe" (seven or more symptoms) and "not severe" for descriptive purposes.

Substance use measures included past 90-day frequencies, in days, of reported use of alcohol, marijuana, powder cocaine, crack, ecstasy, LSD, methamphetamine, and heroin, as well as the non-medical use of prescription benzodiazepines, stimulants, antidepressants and antipsychotics.

Substance dependence was assessed by seven DSM-IV symptoms experienced during the past year (e.g., using more or more often than intended, withdrawal problems), and was dichotomized as "dependent" (three or more symptoms) or "not dependent" for descriptive reporting. Single dichotomous items assessed lifetime prevalence of injection drug use and substance treatment history. Participants were asked about drug overdose histories with the following item: "How many times in your life, if ever, have you had a drug overdose or drug-related emergency?"Participants endorsing such histories were asked to report the number of times they had experienced a drug overdose or emergency, as well as the substances involved.

Several features of NMPOU were also examined as potential predictors of heroin initiation at follow up. As a general instruction, participants were directed not to report use of prescription opioids as instructed by a doctor. We examined length of NMPOU, calculated from reported age at initial NMPOU to present.

Following symptom assessment for DSM-IV dependence described above, participants were asked to indicate the main substance that caused each of these symptoms. Those indicating three or more past year symptoms attributed primarily to prescription opioids were classified as "dependent". Frequency of NMPOU was assessed by asking participants to report the specific number of days they had used opioids non-medically within the 90 days prior to interview.

Routes of prescription opioid administration were assessed by the following item:

Please select all the ways you have used/taken prescription opioids in the past 90 days. Response options included oral (drank, swallowing a whole pill, swallowing a crushed pill, dissolving under the tongue, and parachuting [swallowing a crushed pill inside a piece of paper]), smoked, snorted/sniffed, injected, and rectal/vaginal. For analysis, we examined oral intact (drank or whole pill), oral tampered (crushed pill, parachute, and under tongue), smoked, snorted and injected. Rectal/vaginal administration of prescription opioids was not endorsed by any participant in the selected sample.

Usual source of prescription opioid acquisition was measured by asking participants: In the past 90 days, what was the primary way you got your prescription opioids? Response choices were: more than one doctor, your regular doctor, pain clinic, theft, club/dealer/street buy, sharing/trading, internet, and other. For the purposes of analysis, we collapsed regular 
doctor and pain clinic into a "medical source" category. More than 1 doctor and internet were not endorsed as primary sources for prescription opioids in the selected sample. For analysis, we examined "medical source" versus all other sources.

\subsection{Data Analysis}

Statistical analyses were conducted using IBM SPSS Statistics version 23 and SAS version 9.3 (SAS Institute Inc., Cary, NC), using PROC PHREG and PROC LIFETEST procedures. Descriptive statistics were calculated for the variables of interest, including age, gender, race/ethnicity, physical and mental health, substance use and associated substance problems, including DSM-IV dependence symptoms, and NMPOU characteristics. Univariable comparisons (chi-square and t-tests) were performed to examine baseline characteristics of participants who did and did not initiate heroin use during the follow-up period. Univariable comparisons are not presented for indicators with fewer than 5 participant endorsements. Variables that distinguished heroin initiators from non-initiators (p-values $<=.10$ ) were selected for inclusion in a Cox proportional hazard regression analysis to determine the associations between baseline predictors in relation to likelihood of heroin initiation. In addition to controlling for intervention arm, the Cox regression model included demographic variables that have been associated with NMPOU and heroin use in prior research (Palamar et al., 2016). Kaplan-Meier survival estimates were used to calculate probabilities of time to heroin initiation. Inter-correlations between predictor variables were low (rs=.01-.30), and tests for the violation of the proportional hazard assumption found no evidence of nonproportionality. All two-tailed tests with significant values greater than $95 \%(\mathrm{p}<.05)$ are reported.

\subsection{Results}

Sample characteristics are displayed in Table 1. The overall sample of NMPO users was young, with a mean age of 25.0 years, and was $46.4 \%$ female. Nearly two-thirds (65.0\%) were Hispanic, mirroring the ethnic composition of the Miami metropolitan area.

Despite the sample's young age, physical health problems were prevalent among these heroin-naïve NMPO users. Nearly $30 \%$ of the sample reported experiencing significant pain during the 90 days prior to interview, and $22 \%$ reported that a physical health problem had impaired their daily functioning in the same time period. Prevalence of severe psychological distress was elevated at $48.6 \%$. Less than $1 \%$ reported either an HIV or hepatitis C diagnosis.

In line with study eligibility criteria, NMPO users reported substantial polydrug use, including illicit club drug use and other nonmedical prescription drug use in the 90 days prior to interview. On average, reported use was most frequent for marijuana (63.2 days), alcohol (48.4 days), prescription sedatives (33.4 days), ecstasy (31.9 days), and powder cocaine (31.7 days).

In the context of heavy poly-drug use, indicators of substance use-related problems were also examined. More than two-thirds of the sample (67.5\%) met DSM-IV criteria for substance dependence in the past year. $21.1 \%$ reported a drug overdose or drug-related

Drug Alcohol Depend. Author manuscript; available in PMC 2018 October 01. 
emergency in their lifetime, and half of those had experienced multiple overdose episodes (data not shown). Reported lifetime injection prevalence among NMPO users was 4.0\%.

The sample reported NMPOU for a mean of 5.0 years at the time of the baseline contact. The prevalence of prescription opioid dependence in the past year was $3.4 \%$. On average, frequency of reported NMPOU in the past 90 days was 31.0 days. Oral intact administration was the most commonly reported method of prescription opioid use (94.1\%), however, substantial proportions reported alternate routes as well, including oral tampered administration (22.3\%), and intranasal (9.0\%). More than one-quarter (26.6\%) reported taking prescription opioids by any alternate route in the past 90 days.

A total of 25 NMPOU misusers were prospectively observed to start using heroin over the 12-month follow-up period with a survival rate of .90. Most heroin initiators (60\%) began using heroin at the 3-month interval, 24\% started to use heroin at the 6-month interval, and $16 \%$ reported initial heroin use at the 12-month interval. Comparatively, only one participant without baseline NMPOU indicated heroin onset at follow-up (data not shown).

As shown in Table 1, univariable comparisons found several differences in baseline characteristics between heroin initiators $(\mathrm{N}=25)$ and non-initiators $(\mathrm{N}=298)$, though demographic characteristics were uniformly not associated with heroin initiation in this sample. The likelihood of heroin initiation at follow up was significantly higher among NMPO users reporting current physical health problems at baseline: those with severe pain $\left(X^{2}=2.65, p=.10\right)$ and those reporting impaired physical functioning $\left(X^{2}=3.11, p=.08\right)$ were more likely to initiate heroin compared to their counterparts without these impairments.

In terms of substance use, the likelihood of heroin initiation at follow up was higher among more frequent users of LSD $(t=-3.04 ; p<.01)$. Participants with a lifetime history of drug overdose or emergency were also more likely to report initiating heroin at follow-up compared to their counterparts without an overdose experience $\left(X^{2}=3.64 ; p=.06\right)$.

Several features of NMPOU displayed significant associations with heroin initiation. Participants reporting more days of current NMPOU has a higher likelihood of initiating heroin during the follow-up period ( $t=-1.63 ; p=10$ ). Taking prescription opioids by oral tampering methods was associated with higher likelihood of heroin initiation at follow-up $\left(X^{2}=7.37 ; p<.01\right)$. In addition, participants whose primary method of prescription opioid acquisition involved a medical source were more likely to report heroin initiation at followup than those without a medical source $\left(X^{2}=7.89 ; p<.01\right)$.

Results of the Cox proportional hazard regression predicting initial heroin use are shown in Table 2. Controlling for model covariates, three substance-related behaviors emerged as significant predictors of heroin initiation: LSD use, accessing prescription opioids through a medical source, and ingestion of orally tampered prescription opioids. Specifically, each additional day of using LSD increased the hazard of initiating heroin use by $3 \%$, controlling for model covariates. Those accessing prescription opioids through a medical source were about 5 times more likely to initiate heroin use than participants who accessed prescription opioids through other sources. Those whose route of administration of prescription opioids 
involved oral tampering were about three times more likely to initiate heroin use than those reporting other routes of administration. There was no association between model covariates (experimental arm, age, gender, race/ethnicity) and likelihood of heroin initiation.

\subsection{Discussion}

This prospective study documented heroin initiation among $7.7 \%$ of our young adult sample in the 12 month follow up observation period, suggesting a high level of vulnerability for transition to heroin among NMPO using club goers. The present study adds to the emerging literature on trajectories of NMPOU, and resonates with recent findings identifying specific NMPOU behaviors, such as frequency of nonmedical use and route of administration, as predictive of heroin use onset (Carlson et al., 2016).

In the univariable comparisons, we found that reported severe pain and physical health problems were associated with higher likelihood of heroin initiation at follow-up. These findings are consistent with existing observational data on the associations of NMPOU and physical health co-morbidities (Alford et al., 2015; Blanco et al., 2016; Cicero et al., 2012b; Levi-Minzi et al., 2013; McCabe et al., 2007), and lends support to the idea that selfmedication of untreated or under-treated health problems contributes to NMPOU. Although the present study did not collect information on motivation for NMPOU, Carlson and colleagues (2016) found that self-medication among NMPO users was not associated with heroin use initiation, whereas use to "get high" was.

Frequency of NMPOU may represent a good marker of opioid problem severity, spanning from episodic use to persistent use. In our young adult sample, the more frequent NMPO users had higher likelihood of heroin initiation in univariable analyses, consistent with findings of other research (Carlson et al., 2016; Jones, 2013). More frequent or daily use of opioids may suggest the development of tolerance and dependence (Daniulaitye et al., 2006, Haracopos et al., 2016), which drives the need to acquire more opioids and increases availability and cost pressures on users (Cicero et al., 2014).

At the univariable level we also found that lifetime history of drug overdose or drug emergency was associated with higher likelihood of heroin initiation. Interestingly, the drugs most often mentioned at baseline as involved in emergency episode(s) were alcohol, cocaine, and/or prescription sedatives, rather than prescription opioids. This may be an indicator that a subset of our young adult sample has particularly risky patterns of poly-drug use and concomitant experimentation with multiple substances, which is associated with future heroin initiation. Prior research has demonstrated that previous alcohol and/or other drug use, as well as patterns of poly-drug use, increase the likelihood of NMPOU (Edlund et al., 2010; Wu and Howard, 2007).

In line with other emerging research, our findings indicate that route of administration is a key factor in opioid transitions (Carlson et al., 2016; Lankenau et al., 2012), and may represent an important target for prevention and intervention efforts. As previously observed, the reinforcing effects of opioids are heightened by rapid delivery through altered routes, and individuals often initiate orally and move to more efficient routes, such as snorting and

Drug Alcohol Depend. Author manuscript; available in PMC 2018 October 01. 
smoking, as tolerance develops (Compton and Volkow, 2006; Compton et al., 2016; Volkow and McLellan, 2016). Our findings extend prior research by documenting that oral tampering methods are a very common alternate route of administration, and may be an early antecedent to intranasal and injection use.

Another unique finding of this study is the significant association between primary source of prescription opioid acquisition and the onset of heroin use. Although source of opioid diversion has been related to opioid problem severity and progression in prior research (Cicero et al., 2011; Lankenau et al., 2012), the present study demonstrated that participants who reported acquiring prescription opioids for nonmedical use through a primary medical source had substantially higher odds of endorsing heroin initiation at follow-up. While dealers and sharing/trading medications represented much more common methods of opioid acquisition in our sample, a primary medical source for opioids conferred higher odds of heroin onset. Prior research found that NMPO users in Florida relied heavily on pain clinics and other medical sources for consistent access to opioid medications (Rigg et al., 2010); such access may be key in the development of problematic use and dependence. Although speculative, our findings may be indicative of the changing landscape of reduced access to prescription opioids in Florida through doctors and pain clinics (Delcher et al., 2015; Rutlow et al., 2015; Surratt et al., 2014), such that users are increasingly driven to informal, streetbased drug markets where heroin is more available. Heroin availability and purity was increasing nationally, and in South Florida, during the time period of study data collection (Finklea, 2015).

\subsection{Limitations}

Our study has several limitations. First, while our sample is generally representative of the gender and race/ethnic composition of the Miami area, it is unclear whether our findings are generalizable to community-based young adult populations in different geographic and cultural settings, or those who attend club venues in different contexts. Because study eligibility required nonmedical use of a psychoactive prescription medication at least once in the past 3 months, our bar for study entry was fairly high for nonmedical prescription drug use criteria, which may limit generalizability to other club-going samples. Although other U.S.-based studies of club drug users indicate common NMPOU (Kurtz et al., 2005; Kelly et al., 2013; 2015), prevalence in the present study surpassed these, suggesting that our heavily poly-drug-involved sample that may not be typical of club-going young adults. The influence of NMPOU by injection is also unclear and warrants future research, as only one study participant reported this route of administration. In addition, our data were gathered exclusively from participant self-reports, which have inherent weaknesses in terms of potentially inaccurate recall or biased reporting. Given the high levels of substance use reported, however, and the consistency of reports across CAPI and ACASI modalities, underreporting of drug use would appear to be minimal. As an additional point, outcome data were collected in the context of a low-intensity assessment intervention trial, rather than an observational study. As such, the longitudinal data on heroin initiation we report occurred after exposure to a low-dose intervention, which may have reduced the proportion initiating heroin from that of a truly untreated sample. Nevertheless, the study intervention was limited to a one-session interview assessment, which had no specific focus on NMPOU, but

Drug Alcohol Depend. Author manuscript; available in PMC 2018 October 01. 
gathered general information on patterns of drug use, sexual risk, physical and mental health status. Finally, the observed associations between features of NMPOU and subsequent heroin use may be partially attributable to environmental factors, such as legislative and policy efforts influencing availability and supply, which were unexamined in the current study.

\subsection{Implications}

Limitations aside, this study reports robust estimates from a large young adult sample with prevalent NMPOU. Our findings contribute to the long-standing discussion of prescription opioids as potential precursors to heroin use (Mars et al., 2014; Muhuri et al., 2013; Siegal et al., 2003), and provide new insights into the repertoire of behavioral factors that influence transition to heroin among NMPO users in a sample of young adult club goers. We documented heroin initiation among $7.7 \%$ of our young adult sample in a one year observation period, which resonates with recent estimates from other studies (Carlson et al., 2016), and indicates elevated vulnerability for transition to heroin among NMPO using club goers. Given that our young club-going sample was heavily poly-drug-involved and transitioned to heroin at an alarming rate, more research would appear warranted to examine whether unique aspects of the club culture contribute to the acceleration of this transition, or whether the findings of the association between NMPOU and heroin initiation are largely context independent. Future research should also examine the viability of mounting targeted health promotion or harm reduction activities for this population in various settings, including club venues. Although prior work has documented challenges with health messaging within high-volume urban club settings (Kurtz et al., 2013), the adverse consequences of substance use among this young population require intervention approaches that are feasible to implement in settings where members of this population are routinely found. Exploring novel methods for disseminating NMPOU-related harm reduction information, such as risks of opioid tampering, to this targeted group would appear to be a key priority.

The importance of oral tampering methods in our young adult sample of club drug users, and the association with heroin onset within one year, may indicate the need for further examination of the role of abuse deterrent formulations (ADFs) in opioid prevention efforts. It is conceivable that more widespread development of ADFs may have a significant role in preventing shifts in route of administration, particularly among initially opportunistic, young NMPO users. Pilot data from young adults entering detoxification programs for opioid dependence in South Florida suggest that a substantial proportion of young adults are now initiating NMPOU through alternate routes, wholly bypassing oral use (Levi-Minzi et al., 2015), a pattern that is potentially amenable to reduction with more widespread use of ADFs. Although the role of ADFs in opioid prevention efforts is somewhat controversial (Cicero and Ellis, 2015; Kolodny et al., 2015) our data indicate potential benefits of ADFs in limiting nonmedical opioid initiation through alternate routes, and reducing tampering in novice, experimental and opportunistic young opioid users prior to the onset of opioid dependence. There is a clear need for further controlled studies on patterns and trajectories in routes of opioid administration, which would identify specific intervention points and strategies along the trajectory of NMPOU (Carlson et al., 2016; Haracopos et al., 2016).

Drug Alcohol Depend. Author manuscript; available in PMC 2018 October 01. 


\section{Acknowledgments}

The authors gratefully acknowledge Janet Otachi, MA for her assistance with preparing this

Role of Funding Source

This research was supported by Award Number R01DA019048 from the National Institute on Drug Abuse. The content is solely the responsibility of the authors and does not necessarily represent the official views of the National Institute on Drug Abuse or the National Institutes of Health.

\section{References}

Alford DP, Zisblatt L, Ng P, Hayes SM, Peloquin S, Hardesty I, White JL. SCOPE of pain: An evaluation of an opioid risk evaluation and mitigation strategy continuing education program. Pain Med. 2015; doi: 10.1111/pme.12878

Allman, TD. Miami: City of the Future. University Press of Florida; Gainesville, Florida: 1987.

Blanco C, Wall MM, Okuda M, Wang S, Iza M, Olfson M. Pain as a predictor of opioid use disorder in a nationally representative sample. Am J Psychiatry. 2016; 173:1189-1195. [PubMed: 27444794]

Brady JE, Wunsch H, DiMaggio C, Lang BH, Giglio J, Li G. Prescription drug monitoring and dispensing of prescription opioids. Public Health Rep. 2014; 129:139-147. [PubMed: 24587548]

Brandt, PR. South Beach: From hot to cold, back to hot again. New York Times; 2003. p. F1

Buttram ME, Kurtz SP. Alternate routes of administration among NMPOUrs and associations with sexual HIV transmission risk behaviors. J Psychoactive Drugs. 2016; 48:187-94. DOI: 10.1080/02791072.2016.1187319 [PubMed: 27224253]

Carlson RG, Nahhas RW, Martins SS, Daniulaityte R. Predictors of transition to heroin use among initially non-opioid dependent illicit pharmaceutical opioid users: A natural history study. Drug Alcohol Depend. 2016; 160:127-134. [PubMed: 26785634]

Center for Behavioral Health Statistics and Quality. 2014 National Survey on Drug Use and Health: Detailed Tables. Substance Abuse and Mental Health Services Administration; Rockville, MD: 2015.

Cerdá M, Santaella J, Marshall BDL, Kim JH, Martins SS. Nonmedical prescription opioid use in childhood and early adolescence predicts transitions to heroin use in young adulthood: A national study. J Pediatr. 2015; 167:605-612. [PubMed: 26054942]

Cicero TJ, Ellis MS. Abuse deterrent formulations and the prescription opioid abuse epidemic in the United States: Lessons learned from oxycontin. JAMA Psychiatry. 2015; 72:424-429. [PubMed: 25760692]

Cicero TJ, Ellis MS, Surratt HL. Effect of abuse-deterrent formulation of oxycontin. NEJM. 2012a; 367:187-189. [PubMed: 22784140]

Cicero TJ, Ellis MS, Surratt HL, Kurtz SP. The changing face of heroin use in the United States: A retrospective analysis of the past 50 years. JAMA Psychiatry. 2014; 71:821-826. [PubMed: 24871348]

Cicero TJ, Kurtz SP, Surratt HL, Ibanez GE, Ellis MS, Levi-Minzi MA, Inciardi JA. Multiple determinants of specific modes of prescription opioid diversion. J Drug Issues. 2011; 41:283-304. [PubMed: 22287798]

Cicero TJ, Surratt HL, Kurtz SP, Ellis MS, Inciardi JA. Patterns of prescription opioid abuse and comorbidity in an aging treatment population. J Subst Abuse Treat. 2012b; 42:87-94. [PubMed: 21831562]

Compton W, Jones C, Baldwin G. Relationship between Nonmedical prescription opioid use and heroin use. N Engl J Med. 2016; 374:154-163. [PubMed: 26760086]

Compton WM, Volkow ND. Abuse of prescription drugs and the risk of addiction. Drug Alcohol Depend. 2006; 83:S4-S7. [PubMed: 16563663]

Daniulaityte R, Carlson RG, Kenne D. Initiation to pharmaceutical opioids and patterns of misuse: Preliminary qualitative findings obtained by the Ohio Substance Abuse Monitoring Network. J Drug Issues. 2006; 36:787-808. 
Dart RC, Surratt HL, Cicero TJ, Parrino MW, Severtson SG, Bucher-Bartelson B, Green JL. Trends in opioid analgesic abuse and mortality in the United States. N Engl J Med. 2015; 372:241-8. [PubMed: 25587948]

Dasgupta N, Creppage K, Austin A, Ringwalt C, Sanford C, Proescholdbeall SK. Observed transition from opioid analgesic deaths from heroin. Drug Alcohol Depend. 2014; 145:238-241. [PubMed: 25456574]

Davis CS, Pierce M, Dasgupta N. Evolution and convergence of state laws governing controlled substance prescription monitoring programs, 1998-2011. Am J Public Health. 2014; 104:1389-95. [PubMed: 24922132]

Davis WR, Johnson BD. Prescription opioid use, misuse, and diversion among street drug users in New York City. Drug Alcohol Depend. 2008; 92:1-17. [PubMed: 17826005]

Delcher C, Wagenaar AC, Goldberger BA, Cook RL, Maldonado-Molina MM. Abrupt decline in oxycodone caused mortality after implementation of Florida's Prescription Drug Monitoring Program. Drug Alcohol Depend. 2015; 150:63-68. [PubMed: 25746236]

Dennis, ML. Global Appraisal of Individual Needs Version.5.4. Chestnut Health Systems; Bloomington, Illinois: 2006.

Edlund MJ, Martin BC, Fan MY, Devries A, Braden JB, Sullivan MD. Risks for opioid abuse and dependence among recipients of chronic opioid therapy: Results from the TROUP study. Drug Alcohol Depend. 2010; 112:90-98. [PubMed: 20634006]

Finklea, K. Heroin Trafficking in the United States; Congressional Research Service Report R44599; 2016.

Florida Department of Law Enforcement. Florida Drug Enforcement Teams Strike Down Prescription Drug Abuse. Mar 4. 2012

Frieden TR, Houry D. Reducing the risks of relief: The CDC opioid-prescribing guidelines. N Engl J Med. 2016; 374:1501-1504. [PubMed: 26977701]

Ghafoor, Vl, Phelps, P., Pastor, L. Implementation of a pain medication opioid stewardship program. Am J Health Sys Pharm. 2013; 70:2070, 2074-75.

Hall, JN. Florida Drug Trends Update. Florida Prevention Summit, Florida Alcohol and Drug Abuse Association; Orlando, Florida: 2015. August 4, 2015

Han B, Compton W, Jones C, Cai R. Nonmedical prescription opioid use and use disorders among adults aged 18 through 64 years in the United States, 2003-2013. JAMA. 2015; 314:1468-1478. [PubMed: 26461997]

Haracopos A, Allen B, Paone D. Circumstances and contexts of heroin initiation following nonmedical opioid analgesic use in New York City. Int J Drug Policy. 2016; 28:106-112. [PubMed: 26818082]

Heckathorn DD. Respondent-driven sampling: A new approach to the study of hidden populations. Soc Prob. 1997; 44:174-199.

Inciardi JA, Surratt HL, Kurtz SP, Cicero TJ. Mechanisms of prescription drug diversion among drug involved club and street populations. Pain Med. 2007; 8:171-183. [PubMed: 17305688]

Jones CM. Heroin Use and heroin use risk behaviors among nonmedical users of prescription opioid pain relievers - United States, 2002-2004 and 2008-2010. Drug Alcohol Depend. 2013; 132:95100. [PubMed: 23410617]

Katz N, Fernandez K, Chang A, Benoit C, Butler SF. Internet-based survey of nonmedical prescription opioid use in the United States. Clin J Pain. 2008; 24:528-535. [PubMed: 18574362]

Kelly BC, Parsons JT. Prescription drug misuse among club drug-using young adults. Am J Drug Alcohol Abuse. 2007; 33:875-884. [PubMed: 17994483]

Kelly BC, Vuolo M, Pawson M, Wells BE, Parsons JT. Chasing the Bean: Prescription drug smoking among socially active youth. J Adolesc Health. 2015; 56:632-638. [PubMed: 26003578]

Kelly BC, Wells BE, LeClair A, Tracy D, Parsons JT, Golub SA. Prevalence and correlates of prescription drug misuse among socially active young adults. Int J Drug Policy. 2013; 24:297-303. [PubMed: 23036649]

Kolodny A, Courtwright DT, Hwang CS, Kreiner P, Eadie JL, Clark TW, Alexander GC. The prescription opioid and heroin crisis: A public health approach to an epidemic of addiction. Annu Rev Public Health. 2015; 36:559-574. [PubMed: 25581144] 
Kurtz SP, Buttram ME, Surratt HL. Benzodiazepine dependence among young adult participants in the club scene who use drugs. J Psychoactive Drugs. 2017; 49:39-46. [PubMed: 28001962]

Kurtz SP, Surratt HL, Buttram ME, Levi-Minzi MA, Chen M. Interview as intervention: The case of young adult multidrug users in the club scene. J Subst Abuse Treat. 2013; 44:301-308. [PubMed: 22971689]

Kurtz SP, Inciardi JA, Surratt HL, Cottler L. Prescription drug abuse among ecstasy users in Miami. J Addict Dis. 2005; 24:1-16.

Lankenau SE, Teti M, Silva K, Bloom JJ, Haracopos A, Treese M. Initiation into NMPOU amongst young injection drug users. Int J Drug Policy. 2012; 23:37-44. [PubMed: 21689917]

Levi-Minzi MA, Surratt HL, Kurtz SP, Buttram ME. The Under-treatment of Pain: A prescription for opioid misuse among the elderly. Pain Med. 2013; 14:1719-1729. [PubMed: 23841571]

Levi-Minzi, MA., Surratt, HL., O'Grady, CE., Kurtz, SP. Examining the relationship between social context and prescription opioid initiation routes among young adults entering detoxification; Poster presented at the 77th Annual Meeting of the College on Problems of Drug Dependence; Phoenix, Arizona. 2015.

Mars SG, Bourgois P, Karandinos G, Montero F, Ciccarone D. "Every never I ever said came true": Transitions from opioid pills to heroin injecting. Int J Drug Policy. 2014; 25:257-266. [PubMed: 24238956]

Martins SS, Segura LE, Santaella-Tenorio J, Perlmutter A, Fenton MC, Cerda M, Keyes KM, Ghandour LA, Storr CL, Hasin DS. Prescription opioid use disorder and heroin use among 12-34 year olds in the United States from 2002 to 2014. Addict Behav. 2017; 65:236-241. [PubMed: 27614657]

McCabe SE, Boyd CJ, Cranford JA, Teter CJ. Motives for non-medical use of prescription opioids among high school seniors in the United States: Self treatment and beyond. Arch Pediatr Adolesc Med. 2009; 163:739-744. [PubMed: 19652106]

McCabe SE, Cranford JA, Boyd CJ, Teter CJ. Motives, diversion and routes of administration associated with nonmedical use of prescription opioids. Addict Behav. 2007; 32:1-16. [PubMed: 16644136]

Muhuri, PK., Gfroerer, JC., Davies, MC. Associations of Nonmedical Pain Reliever Use and Initiation of Heroin Use in the United States Center for Behavioral Health Statistics and Quality Data Review. Substance Abuse and Mental Health Services Administration; Rockville, MD: 2013.

National Drug Intelligence Center. Florida Drug Threat Assessment. United States Department of Justice; Johnstown, PA: 2003. Report 2003-S0381FL-001

Office of National Drug Control Policy, Executive Office of the President of the United States. National Drug Control Strategy. 2014. Retrieved from https://obamawhitehouse.archives.gov/sites/ default/files/ondcp/policy-and-research/ndcs_2014.pdf. Accessed February, 07, 2017

Palamar J, Shearston J, Dawson E, Mateu-Gelabert P, Ompad D. Nonmedical opioid use and heroin use in a nationally representative sample of US high school seniors. Drug Alcohol Depend. 2016; 158:132-138. [PubMed: 26653341]

Perrone, D. The high life: Club kids, harm and drug policy. Criminal Justice Press; Monsey, NJ: 2009.

Peters P, Pontones P, Hoover K, Patel M, Galang R, Shields J, Blosser S, Spiller M, Combs B, Switzer W, Conrad C, Gentry J, Khudyakov Y, Waterhouse D, Owen S, Chapman E, Roseberry J, McCants V, Weidle P, Broz D, Samandari T, Mermin J, Walthall J, Brooks J, Duwve J. HIV Infection Linked to Injection Use of Oxymorphone in Indiana, 2014-2015. N Engl J Med. 2016; 375:22939. [PubMed: 27468059]

Portes, A., Stepick, A. City on the edge: The transformation of Miami. University of California Press; Berkley and Los Angeles, California: 1993.

Rigg K, March SJ, Inciardi JA. Prescription drug abuse and diversion: The role of the pain clinic. J Drug Issues. 2010; 40:681-702. [PubMed: 21278927]

Rutlow L, Chang HY, Daubresse M, Webster DW, Stuart EA, Alexander G. Effect of florida's prescription drug monitoring program and pill mill laws on opioid prescribing and use. JAMA Intern Med. 2015; 175:1642-1649. [PubMed: 26280092]

Drug Alcohol Depend. Author manuscript; available in PMC 2018 October 01. 
Salas J, Scherrer JF, Lustman PJ, Schneider D. Racial differences in the association between nonmedical prescription opioid use, abuse/dependence and major depression. Subst Abuse. 2016; $37: 25-30$.

Siegal HA, Carlson RG, Kenne DR, Swora MG. Probable relationship between opioid abuse and heroin use. Am Fam Phys. 2003; 67:945.

Stover MW, Davis JM. Opioids in pregnancy and neonatal abstinence syndrome. Semin Perinatol. 2015; 39:561-565. [PubMed: 26452318]

Surratt HL, Kurtz SP, Cicero TJ. Alternate routes of administration and risk for HIV among prescription opioid abusers. J Addict Dis. 2011; 30:1-8. [PubMed: 21218305]

Surratt HL, O'Grady CL, Kurtz SP, Stivers Y, Cicero TJ, Dart RC, Chen M. Reductions in prescription opioid diversion following recent legislative interventions in Florida. Pharmacoepidemiol Drug Saf. 2014; 23:314-320. [PubMed: 24677496]

U.S. Census Bureau. State and County Quickfacts, Miami-Dade County. Florida: 2015. Retrieved from http://www.census.gov/quickfacts/table/PST045215/12086. Accessed December 12, 2016

Volkow ND, McLellan AT. Opioid abuse in chronic pain - Misconceptions and mitigation strategies. N Engl J Med. 2016; 374:1253-1263. [PubMed: 27028915]

Wu LT, Howard MO. Is inhalant use a risk factor for heroin and injection drug use among adolescents in the United States? Addict Behav. 2007; 32:265-281. [PubMed: 16713124]

Young AM, Havens JR, Leukefeld CG. Route of administration for illicit prescription opioids: A comparison of rural and urban drug users. Harm Reduct J. 2010; 7:1-7. [PubMed: 20047690]

Drug Alcohol Depend. Author manuscript; available in PMC 2018 October 01. 


\section{Highlights}

- Young adults in the club scene have high levels of nonmedical prescription opioid use

- Heroin onset occurred in $7.7 \%$ of nonmedical opioid users by 12 month follow up

- Opioid ingestion through oral tampering methods is predictive of heroin initiation 


\section{Table 1}

\section{Baseline Characteristics of NMPO Users}

\begin{tabular}{|c|c|c|c|c|}
\hline & & \multirow[b]{2}{*}{ Total } & \multicolumn{2}{|c|}{ Initiated Heroin Use } \\
\hline & & & No & Yes \\
\hline & & $\mathbf{N}(\%)$ & $\mathbf{N}(\%)$ & $\mathbf{N}(\%)$ \\
\hline & & $323(100.0 \%)$ & $298(92.3 \%)$ & $25(7.7 \%)$ \\
\hline \multicolumn{5}{|l|}{ Demographics } \\
\hline Age: & $\begin{array}{l}18-24 \\
25-29 \\
30+ \\
\text { mean }(S D)\end{array}$ & $\begin{array}{l}176(54.5 \%) \\
78(24.1 \%) \\
69(21.4 \%) \\
25.0(5.24)\end{array}$ & $\begin{array}{c}166(94.3 \%) \\
68(87.2 \%) \\
64(92.8 \%) \\
25.0(5.2)\end{array}$ & $\begin{array}{c}10(5.7 \%) \\
10(12.8 \%) \\
5(7.2 \%) \\
25.8(5.4)\end{array}$ \\
\hline Gender: & Female & $150(46.4 \%)$ & $140(93.3 \%)$ & $10(6.7 \%)$ \\
\hline \multirow[t]{4}{*}{ Race/ethnicity: } & Hispanic & $210(65.0 \%)$ & $196(93.3 \%)$ & $14(6.7 \%)$ \\
\hline & African American/Black & $77(23.8 \%)$ & $69(89.6 \%)$ & $8(10.4 \%)$ \\
\hline & White & $26(8.0 \%)$ & $23(88.5 \%)$ & $3(11.5 \%)$ \\
\hline & Other & $10(3.1 \%)$ & $10(100.0 \%)$ & $0(0.0 \%)$ \\
\hline \multicolumn{5}{|l|}{ Health } \\
\hline Significant pain (past 90 days) & & $96(29.7 \%)$ & $85(88.5 \%)$ & $11(11.5 \%)^{+}$ \\
\hline Health problem interference (past 90 days) & & $71(22.0 \%)$ & $62(87.3 \%)$ & $9(12.7 \%)^{+}$ \\
\hline HIV-positive & & $3(0.9 \%)$ & - & - \\
\hline HCV-positive & & $1(0.3 \%)$ & - & - \\
\hline Severe mental distress (past year) & & $157(48.6 \%)$ & $142(90.4 \%)$ & $15(9.6 \%)$ \\
\hline \multicolumn{5}{|l|}{ Substance use (days in past 90) } \\
\hline Days Alcohol & $\operatorname{mean}(S D)$ & $48.4(25.2)$ & $48.0(25.3)$ & $52.9(24.3)$ \\
\hline Days Marijuana & $\operatorname{mean}(S D)$ & $63.2(31.6)$ & $62.9(31.4)$ & $66.7(34.4)$ \\
\hline Days Cocaine (powder) & $\operatorname{mean}(S D)$ & $31.7(26.0)$ & $31.6(26.2)$ & $33.9(24.3)$ \\
\hline Days Crack cocaine & $\operatorname{mean}(S D)$ & $3.7(14.2)$ & $3.5(13.7)$ & $5.8(19.5)$ \\
\hline Days Ecstasy & $\operatorname{mean}(S D)$ & $31.9(23.8)$ & $31.7(23.9)$ & $33.5(22.9)$ \\
\hline Days Heroin & $\operatorname{mean}(S D)$ & $0.0(0.0)$ & - & - \\
\hline Days LSD & mean $(S D)$ & $5.5(11.8)$ & $5.0(10.4)$ & $12.3(21.5)^{* * *}$ \\
\hline Days Methamphetamine & $\operatorname{mean}(S D)$ & $1.9(7.8)$ & $2.0(8.0)$ & $0.9(2.3)$ \\
\hline Days Prescription stimulants & $\operatorname{mean}(S D)$ & $10.1(18.5)$ & $10.2(18.5)$ & $8.5(19.3)$ \\
\hline Days Prescription sedatives & $\operatorname{mean}(S D)$ & $33.4(28.8)$ & $33.2(28.8)$ & $36.0(29.4)$ \\
\hline Days Prescription antidepressants & $\operatorname{mean}(S D)$ & $6.7(17.9)$ & $6.5(17.6)$ & $8.7(21.9)$ \\
\hline Days Prescription antipsychotics & $\operatorname{mean}(S D)$ & $5.7(16.3)$ & $5.8(16.6)$ & $4.8(13.2)$ \\
\hline \multicolumn{5}{|l|}{ Substance-related problems } \\
\hline Substance dependence (past year) & & $218(67.5 \%)$ & $198(90.8 \%)$ & $20(9.2 \%)$ \\
\hline Drug overdose or drug-related emergency (lifetime) & & $68(21.1 \%)$ & $59(86.8 \%)$ & $9(13.2 \%)^{+}$ \\
\hline Substance abuse treatment (lifetime) & & $88(27.2 \%)$ & $80(90.9 \%)$ & $8(9.1 \%)$ \\
\hline Drug injection (lifetime) & & $13(4.0 \%)$ & $11(84.6 \%)$ & $2(15.4)$ \\
\hline
\end{tabular}

Drug Alcohol Depend. Author manuscript; available in PMC 2018 October 01. 


\begin{tabular}{|c|c|c|c|c|}
\hline & & \multirow[b]{2}{*}{ Total } & \multicolumn{2}{|c|}{ Initiated Heroin Use } \\
\hline & & & No & Yes \\
\hline & & $\mathbf{N}(\%)$ & $\mathbf{N}(\%)$ & $\mathbf{N}(\%)$ \\
\hline & & $323(100.0 \%)$ & $298(92.3 \%)$ & $25(7.7 \%)$ \\
\hline \multicolumn{5}{|c|}{ Nonmedical prescription opioid use (NMPOU) } \\
\hline Years of NMPOU & $\operatorname{mean}(S D)$ & $5.0(4.1)$ & $5.0(4.1)$ & $5.6(4.0)$ \\
\hline Age at first NMPOU & $\operatorname{mean}(S D)$ & $20.0(4.6)$ & $20.0(4.6)$ & $20.2(4.2)$ \\
\hline Days NMPOU (past 90) & $\operatorname{mean}(S D)$ & $31.0(25.8)$ & $30.3(25.7)$ & $39.1(26.8)^{+}$ \\
\hline Prescription opioid dependence (past year) & & $11(3.4 \%)$ & $8(72.7 \%)$ & $3(27.3 \%)$ \\
\hline \multirow[t]{6}{*}{ Routes of NMPO Administration: } & Oral & $304(94.1 \%)$ & $279(91.8 \%)$ & $25(8.2 \%)$ \\
\hline & Oral, tampered & $72(22.3 \%)$ & $58(84.1 \%)$ & $11(15.9 \%)^{*}$ \\
\hline & Smoking & $10(3.1 \%)$ & $9(90.0 \%)$ & $1(10.0 \%)$ \\
\hline & Snorting & $29(9.0 \%)$ & $25(86.2 \%)$ & $4(13.8 \%)$ \\
\hline & Injecting & $1(0.3 \%)$ & - & - \\
\hline & Any alternate route & $86(26.6 \%)$ & $74(86.0 \%)$ & $12(14.0 \%)^{*}$ \\
\hline \multirow[t]{5}{*}{ Primary Source of Opioids: } & Medical & $15(4.6 \%)$ & $11(73.3 \%)$ & $4(26.7 \%)^{*}$ \\
\hline & Theft & $10(3.1 \%)$ & $9(90.0 \%)$ & $1(10.0 \%)$ \\
\hline & Dealer/Club/Street buy & $208(64.4 \%)$ & $192(92.3 \%)$ & $16(7.7 \%)$ \\
\hline & Sharing/Trading & $89(27.6 \%)$ & $85(95.5 \%)$ & $4(4.5 \%)$ \\
\hline & Other & $1(0.3 \%)$ & - & - \\
\hline
\end{tabular}

${ }^{+}$Notes: $\mathrm{p} \leq 10$;

*

$\mathrm{p} \leq 05$;

* $\mathrm{p} \leq 01$

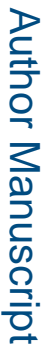

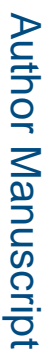

Drug Alcohol Depend. Author manuscript; available in PMC 2018 October 01. 


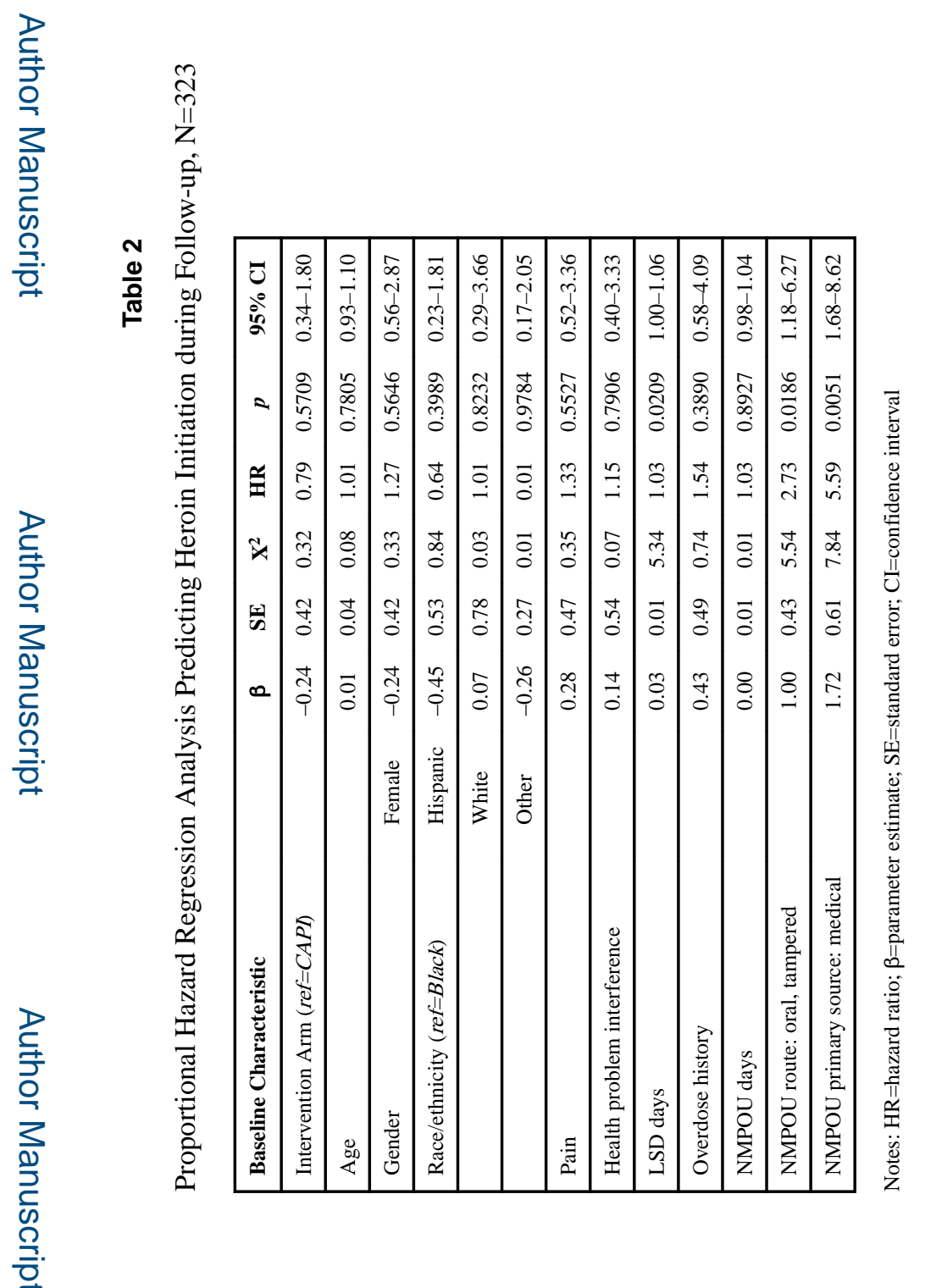

